\title{
SOBRE LA DEFINICIÓN DE FENOMENALISMO
}

1. ¿Son indiscernibles esse $y$ percipi?

No es fácil determinar con pulcritud qué deba entenderse o en qué consista una doctrina filosófica fenomenalista; la dificultad estriba en que muy diversos sistemas filosóficos han sido calificados de fenomenalistas y en que esto, precisamente, complica la tarea de delimitar el sentido en que debamos hablar de "fenomenalismo", la de señalar los problemas relevantes de carácter epistemológico que plantea una teoría filosófica semejante y, en su caso, apuntar inequívocamente sus soluciones hasta donde sea posible.

Por fenomenalismo se ha entendido a menudo una teoría filosófica que pretende establecer argumentos válidos para negar que existan objetos físicos o materiales independientemente de los contenidos sensibles, "ideas" o sensaciones. A esta línea de pensamiento fenomenalista pertenecen sistemas filosóficos como el de Berkeley y el de Ernst Mach, en los que los llamados "objetos exteriores" se reducen o a una mera collection de ideas o a una serie de elementos sensoriales. Pero también se ha interpretado de fenomenalista una teoría filosófica que si bien no niega la existencia de los objetos exteriores, niega en cambio que sea posible su conocimiento. Fenomenalismos de este género se han atribuido a Hume y a Kant, con las diferencias de rigor. ${ }^{1}$ Lo que es más, una teoría filosófica que ni siquiera se plantea el problema de la existencia y del conocimiento de los "objetos exteriores", por considerarlo ajeno a la ciencia filosófica, que no se compromete con el problema de si tales objetos son "dados" inmediatamente en la percepción o si son "creados" por el pensamiento, sino que prefiere hablar de todos los objetos como "constructos" a partir de "vivencias elementales" (Elementarerlebnisse), como la que expuso Carnap en Der logische Aufbau der Welt, ha sido igualmente interpretada como una teoría filosófica fenomenalista, ${ }^{2}$ a pesar de que en esta obra se considera que el fenomenalismo es una metafísica superada por la logische Aufbau. Es que en esta obra Carnap había adoptado como divisa de la filosofía una máxima de Russell establecida por éste en 1914 como la máxima suprema del filosofar científico: dondequiera que sea posible, las construcciones lógicas deben remplazar a las en-

1 Al respecto se puede ver, Jonathan Bennett, Kant's Analytic, Cambridge University Press, 1966, $\S 3^{2}$, pp. 127-128; $\S 5^{2}$, pp. $215^{-216}$.

2 Cf. Ernest Nagel, The Structure of Science, New York, Harcourt, Brace \& World, Inc., 1961, cap. 6 , II, p. 129 , nota. 
tidades inferidas. ${ }^{3}$ La aplicación de este principio metódico llevó a Russell a decir que los objetos físicos no son sustancias distintas de la serie de datos sensibles en que aparecen, que son por el contrario "construcciones lógicas" constituidas a partir de clases de datos sensibles directamente percibidos o perceptibles, con lo que quería significar, no que los objetos físicos se reduzcan literalmente a un conjunto de contenidos sensoriales o "ideas" en el sentido de Berkeley, sino más bien que todo enunciado que se refiere a un objeto físico es reducible a una clase de enunciados lógicamente equivalente al primero en donde los miembros de esta clase no mencionan más el objeto físico, sino exclusivamente datos sensibles. Más adelante ofreceremos las razones por las que se ha preferido llamar "fenomenalismo formal" a este tipo de reduccionismo. Queremos por ahora plantear ciertas cuestiones relacionadas con el reduccionismo característico del fenomenalismo sustentado por Berkeley y por Hume, como quiera que es a estos filósofos, particularmente a Berkeley, a quienes se ha atribuido la paternidad de los modernos fenomenalismos, y que de ellos parten en la historia moderna los problemas más debatidos en nuestro tiempo sobre el tema que aquí tratamos. Nuestra primera cuestión es ésta: ¿son indiscernibles esse y percipi, como sostienen Berkeley y Hume a su manera, en qué sentido lo son y con qué consecuencias? Creemos que se puede llegar a definir el fenomenalismo después de discutir cuestiones como éstas mejor que partiendo de la definición misma.

La teoria del conocimiento de Berkeley, si se la reduce al enunciado “esse est percipi", en donde "est" establece una relación de identidad, no es más que la expresión y la defensa apasionada, como sabemos, del carácter completamente tautológico de ese enunciado. Si ser es idéntico a ser percibido, si se establece una perfecta identidad entre tal o cual objeto existente y tal o cual idea o "collection" de ideas, entonces es contradictorio afirmar que existen objetos distintos de las ideas (o percepciones). Lo que sostiene Berkeley es que nosotros no podemos formarnos ninguna idea del ser o existencia de un objeto independientemente de la idea de ese objeto mismo, puesto que la idea del ser o existencia de un objeto es ya la idea de ese objeto mismo. Por consiguiente, si la idea de la existencia de un objeto se reduce a la idea de ese objeto mismo, entonces, dado que ser objeto es ser percibido, la idea del objeto se reduce, a la vez, al objeto mismo. O sea, para resumir, $(I)$ la idea de la existencia de un objeto es equivalente a la idea del objeto mismo, (2) puesto que esse est percipi, la idea del objeto es equivalente, a la vez, al objeto mismo. Queda por ver (3) si asentada la equivalencia entre la idea o percepción del objeto con el objeto mismo (existencia) y, por simple simetría, la equivalencia entre el objeto y la idea o percepción del mismo, no se siguen de ello enunciados triviales tales como "lo que existe es lo que existe"

3 B. Russell, "The relation of sense-data to physics", Mysticism and Logic, London, Allen \& Unwin, 1959, p. 155. 
y "lo que es percibido es lo que es percibido", justamente porque esse est (=) percipi es una tautología.

En relación con lo que acabamos de deçir hay un texto de Berkeley en que éste desafía al lector a que "trate de separar en sus propios pensamientos el ser de una cosa sensible de la percepción de ella". ${ }^{4}$ Berkeley considera, por cierto, que con esto está proponiendo una imposibilidad, pues, según él, no es posible percibir el ser de un objeto independientemente de la percepción del objeto mismo, de modo que no es posible la idea del ser de un objeto independientemente de la idea del objeto mismo; la idea del ser de un objeto se reduce a la idea del objeto mismo y, puesto que esse est percipi, la idea del objeto se reduce al objeto mismo. Pues bien, precisamente porque Berkeley considera que es imposible establecer la separación a que alude el texto que acabamos de citar, concluye que la existencia de objetos materiales, esto es, la existencia de objetos "extramentales" independientes de los conteniùos inmediatos de la percepción, es, inevitablemente, también imposible. Como veremos más detenidamente en el siguiente parágrafo, Berkeley opone sistemáticamente dos sentidos de la expresión "objeto material". Si por objeto material se entiende "algo" inobservable que sustenta las cualidades sensibles, algo que trasciende a las "ideas" de sensación y que como tal existe sin ser percibido, en este caso, partiendo de la premisa de que esse est $(=)$ percipi, sería contradictorio afirmar, como aquí se hace, que existe un objeto semejante, pues equivale a decir que el objeto en cuestión existe en tanto que es percibido y que no es percibido. En consecuencia es necesario negar no sólo que exista, sino que pueda existir, un objeto material entendido de esta manera, "si es que puede negarse lo que nunca ha existido ni siquiera en la imaginación". 5 En cambio si por objeto material se entiende una mera combinación de cualidades sensibles o una mera reunión de ideas de sensación, en este otro caso, puesto que la premisa de que parte Berkeley es una tautología y puede expresarse igualmente así: percipi est $(=)$ esse, sería contradictorio negar que el objeto en cuestión existe, pues equivaldría ahora tanto como a decir que tal objeto, en la medida en que es percibido, existe y que no existe en cuanto es percibido. En consecuencia es necesario afirmar que un objeto material, entendido de esta segunda manera, no sólo existe, sino que es lo único que puede existir. Dados estos dos sentidos de la expresión "objeto material" con que opera Berkeley, y dada la premisa tautológica a partir de la cual rechaza el primero y sostiene el segundo, se puede pensar que si fuera posible discernir la menor laguna entre esse y percipi sería también posible

4 G. Berkeley, The Principles of Human Knowledge, London, The Fontana Library, 196 \&, I, § 6, p. 68. (En adelante se citará la misma edición con las iniciales P.H.K.). La tesis aquí sustentada equivale a decir que el término "existencia" no es un predicado, no designa un atributo de los objetos ni tiene, por tanto, sentido descriptivo, sino que denota el objeto mismo.

5 P.H.K., I, §37, p. 82. 
afirmar con algún fundamento, contra lo que Berkeley considera imposible, que los objetos materiales pueden existir sin ser percibidos, y asimismo, contra lo que considera la única posibilidad, que pueden ser percibidos sin que por eso mismo existan, por lo menos tal como son percibidos. Pero esta doble posibilidad es la que Berkeley niega sistemáticamente, y se trata de ver ahora en qué sentido son indiscernibles esse y percipi para que se niegue esa doble posibilidad y qué consecuencias se derivan de ello. Mas queremos tener en cuenta simultáneamente algunas de las opiniones de Hume que también pueden calificarse tentativamente de fenomenalistas.

En efecto, la sección VI de la Segunda Parte y la sección II de la Cuarta Parte del Primer Libro del Treatise of Human Nature de Hume ("Of the ideas of existence, and of external existence" y "Of scepticism with regard to the senses", respectivamente) han sido consideradas como una expresión más del fenomenalismo representado por Berkeley, con las diferencias que luego señalaremos. ${ }^{6}$ Hume sostiene en la referida sección VI del Primer Libro del Treatise, Segunda Parte, que el espíritu humano no puede en modo alguno conocer, aprehender o percibir, algo que no sea o una "impresión" sensible o una "idea" en que aquélla se representa, que no puede conocerse sino las "percepciones", pues la percepción se desdobla en impresiones e ideas. Lo que aquí afirma Hume expresamente es que "nada puede presentarse realmente al espíritu sino sus percepciones o impresiones e ideas", y que "puesto que nada puede presentarse al espiritu que no sean las percepciones, puesto que todas las ideas se derivan de algo previamente presente al espíritu, se sigue de aquí que nos es imposible concebir o formar siquiera una idea de algo especificamente diferente de las ideas e impresiones". $7 \mathrm{Y}$ en la sección II de la Cuarta Parte, al final, concluye Hume que puesto que es ilusorio pensar que existen "objetos exteriores" y, además, nosotros no podemos concebir otra cosa que no sean las percepciones, "podemos muy bien suponer en general, pero nos es imposible concebir de un modo distinto que los objetos, en su naturaleza, no son en absoluto exactamente lo mismo que las percepciones". 8 Nos encontramos de nuevo aquí con el mismo desafío de Berkeley. Lo que en el fondo sostienen tanto Berkeley como Hume es que quien tratara de

6 D. G. C. Macnabb, editor del Treatise de Hume en la serie "The Fontana Philosophy", segunda edición 1967, y autor de un estudio introductorio a esta obra, escribió hace tiempo un artículo sobre fenomenalismo en el que considera que Hume no puede ser un fenomenalista, porque no "ofrece una respuesta positivista a cuestiones filosóficas acerca de los objetos materiales", sino que su respuesta es a este respecto "meramente escéptica". Cf., de Macnabb, "Phenomenalism", Proceedings of the Aristotelian Society, vol. XLI, 1941, p. 67. Macnabb, sin embargo, no toma en cuenta los dos sentidos aludidos anteriormente en que Berkeley $y$ también Hume se refieren constantemente a los "objetos materiales". Luego veremos en qué sentido es Hume un fenomenalista.

7 D. Hume, A Treatise of Human Nature, London, The Fontana Library, 1967, I, ii, 6, p. 113. Subrayado mío. (Se citará en adelante con las iniciales $T$. H. N.; los números $I$, ii, 6, corresponden, respectivamente, al Libro, la Parte y la Sección).

\& T. H. N. I., iv, 2, p. 268. 
separar o distinguir "especificamente" la existencia o ser de un objeto sensible de la percepción de él, no estaría sino pretendiendo violar, a su respecto, el principio de identidad de los indiscernibles. Berkeley insiste, en efecto, en que "así como me es imposible ver o sentir alguna cosa sin una sensación real de esa cosa, del mismo modo me es imposible concebir en mis pensamientos cualquier cosa sensible $\mathrm{u}$ objeto distinto de la sensación o percepción de él". ${ }^{9}$ En este texto, como en los de Hume, vemos el paso que ambos filósofos dan, por vía de identidad, de la sensación presente al concepto o idea del objeto existente, y de aquí al objeto mismo; en consecuencia, la afirmación de que es imposible concebir o formarse una idea de algún objeto "específicamente" diferente de la sensación o impresión sensible sólo puede provenir de que ambos filósofos parten de la identificación de los objetos con las sensaciones, es decir, con las "ideas". Sobre el particular nada tiene que ver que Hume divida la percepción en impresiones e ideas, porque esta división se basa únicamente en el grado de vivacidad de la percepción; el objeto mismo es idéntico a la impresión o a la idẹa según el grado de intensidad con que se hace presente. Ahora bien, ¿en qué sentido es aplicable el principio de identidad de los indiscernibles a esos objetos que en Berkeley y Hume se llaman indistintamente "ser" o "existencia", "idea" o "percepción"?

Observemos antes que nuestra cuestión no se refiere, como es obvio, a si es posible concebir, en términos de Berkeley y Hume, la identidad de un objeto (o de una percepción) consigo mismo, sea su identidad numérica o su identidad específica. Hume, que es más explícito al respecto, afirma que hay una oposición inconciliable entre atribuir identidad a una percepción y admitir al mismo tiempo lo que constituye la naturaleza misma de la percepción, esto es, su carácter siempre diferente, variable y discontinuo (interrupted), pues la identidad de un objeto consigo mismo supone constancia, continuidad (uninterruptedness) e invariabilidad (invariableness). ${ }^{10}$ Ahora bien, puesto que, en realidad, cuando percibimos lo que llamamos un mismo objeto en distintos momentos a igual o diferentes distancias y desde distintos ángulos, toda percepción es distina y separable, puesto que el espíritu no es más que "una suerte de teatro donde hacen su aparición sucesivamente diversas percepciones, donde éstas pasan, vuelven a pasar, se deslizan y combinan en una variedad infinita de estados y posiciones", 11 Hume considera que la atribución de identidad sólo proviene de confundir una simple relación de semejanza entre las percepciones con otra relación de semejanza "que el acto del espíritu [la imaginación] al contemplar una sucesión de objetos semejantes, le atribuye a aquélla (bears to that) al contemplar un objeto idéntico".12

9 P. H. K., I, § 5, p. 67 . Subrayado mío.

10 G. T. H. N., I, iv, 2, pp. $25^{6-257}$.

$11 T . H . N .$, I, iv, 6, p. 302 .

12 T. H. N., I, iv, 2, p. 255 nota. Aquil aparece un problema particularmente importante desde el punto de vista de la teoría causal de la percepción que luego examinare- 
Esto, exclusivamente, es lo que da lugar a que una mera sucesión de apariencias discontinuas, donde sólo privan relaciones de semejanza, sea complementada con el sobrecargo de un objeto idéntico imaginario que llena los intervalos entre esas apariencias. Esta identidad de un objeto consigo mismo, entendida como una sustancia material que permanece la misma bajo las diversas formas en que ordinariamente percibimos un cuerpo, es la que Berkeley rechaza sistemáticamente por contradictoria. ${ }^{13}$

Nuestra cuestión se refiere más bien a si un objeto que, según Berkeley y Hume, no es susceptible de identidad consigo mismo en el sentido antes aludido es, no obstante, idéntico a ser percibido y, por consiguiente, a si las palabras "esse" y "percipi" no son sino dos nombres para denotar la misma cosa. Tengamos presente, en primer lugar, que lo que ambos filósofos entienden en rigor por una cosa no es más que una collection de cualidades sensibles (ideas o percepciones), ${ }^{14}$ y en segundo lugar, que solamente de esta manera es planteable la pregunta por el sentido en que sea aplicable el principio de la identidad de los indiscernibles a los objetos que se designan indistintamente "esse" o "percipi", "ser" o "idea", como pasamos de inmediato a verlo.

Cabe, sobre el particular, una primera posibilidad, a saber, que lo que designa el término "esse", es decir, un ser particular, y lo que designa el término "percipi", esto es, un conjunto de ideas, sean recíprocamente idénticos porque el conjunto o colección de cualidades que integran un ser particular sea exacta y simétricamente idéntico al conjunto de sensibles o de ideas, y por lo tanto, que al decir de un ser particular que es idéntico a un conjunto de ideas no estemos diciendo sino que un conjunto de cualidades es (E) un conjunto de sensibles y que ambos son un mismo conjunto de cualidades-sensibles, pero que, aun entonces, no pudiera saberse si esse y percipi son idénticos porque éstos no se definieran exclusivamente por un conjunto de cualidades-sensibles. Es claro que aquí estaríamos ante una tesis enteramente sustancialista. En efecto, si esse y percipi no se definieran como idénticos simétricamente por un mero conjunto de cualidades-sensibles, si no pudieran definirse por la fórmula $(x=y)=(F)(F(x) \leftrightarrow F(y))$, quedaría todavía abierta la posibilidad de que, aun correspondiéndose exactamente en el mismo conjunto de cualidades-sensibles, no fueran idénticos, sino distintos, pues no se definen por un mero conjunto de cualidades-sensibles. ${ }^{15}$ Pero

mos; pues si no hay identidad del objeto en medio de los distintos datos sensibles, no podemos atribuir éstos a un objeto exterior, como pretenderia hacerlo un realista ingenuo; pero si en esto tiene razón Hume, el hecho de que al menos haya semejanza entre los datos sensibles, plantea la cuestión acerca de su origen común más allá de los datos sensibles.

13 Cf. P. H. K., I, §95, p. 112.

14 Berkeley, $P . H$. K., I, $\S \S 1$ y 37, pp. 65 y 82 . Hume, T. H. N., I, i. 6, p. 60.

15 B. Russell, An Inquiry Into Meaning and Truth, London, Penguin Books, 1962, cap. 6, p. 92, y cap. 8 , p. 123 . 
ambos filósofos, como hemos visto, declaran que puesto que entre un objeto o ser particular y una idea o conjunto de ideas no hay ninguna diferencia, es imposible concebir o formarse una idea de algún objeto distinto o "específicamente" diferente de la percepción. En consecuencia, el principio de la identidad de los indiscernibles no sería aplicable a esse y percipi en el sentido en que sería aplicable, si fuera posible, en el marco de una tesis sustancialista que ni Berkeley ni Hume sustentan, sentido que llamaremos sintético, para seguir en esto una distinción de Russell, pues aquí los términos de la relación de identidad no se definen por la suma, exclusivamente, de sus cualidades-sensibles y, por lo mismo, subsiste la posibilidad de que ambos sean diferentes aun cuando sean idénticos en la suma de todas sus cualidadessensibles.

Quedaría una segunda posibilidad de aplicar a esse y percipi el principio de la identidad de los indiscernibles, en verdad la más consecuente con la doctrina fenomenalista de Berkeley y de Hume, esto es, la de que lo que designa el término "esse" y lo que designa el término "percipi" sean idénticos porque un ser particular cualquiera y el conjunto de ideas correspondiente se definan exactamente por la misma suma de cualidades-sensibles sine re substante, y por lo tanto, exclusivamente por ella. Así, por ejemplo, nos dice Berkeley, una manzana es solamente un conjunto de ideas, ${ }^{16}$ indicando con esto dos cosas a la vez, primera, que una manzana es idéntica a un conjunto de cualidades-sensibles, tales como un color, un sabor, olor, figura y consistencia determinados, y segunda, que este conjunto de cualidadessensibles es idéntico al conjunto de ideas en cuestión, pues las cualidades "no son otra cosa que sensaciones o ideas". ${ }^{17}$ En virtud de esto, Berkeley afirma más adelante que "en tanto que atribuimos a las cosas que no piensan una existencia real distinta de su ser percibida, no sólo nos es imposible conocer con evidencia la naturaleza de cualquier ser real que no piensa, sino incluso que existe"' ${ }^{18} \mathrm{El}$ supuesto de que hay una diferencia entre cosas $\mathrm{e}$ ideas, entre esse y percipi, no sólo nos llevaría a afirmar, como deciamos anteriormente, que las cosas pueden existir sin ser percibidas, sino también que pueden ser percibidas sin que existan tal como se las percibe. Pero Berkeley, partiendo de la indiscernibilidad de esse y percipi, considera que tal supuesto, aparte de ser una contradicción, es la verdadera raiz del escepticismo, pues en ese supuesto, pregunta, “cómo puede conocerse que las cosas que se perciben concuerdan con aquellas que no se perciben o que existen fuera de la mente?" 19 Pensamos, en cambio, que éste debió haber sido el problema inicial, no por levantar el polvo para lamentarnos después de que no se ve, según se queja Berkeley en la introducción a los Principles, sino porque

16 Berkeley, P. H. K., I, \& 1, p. 65.

17 P. H. K., I, § 78 , p. 10 .

$18 P . H . K ., \mathrm{I}, \S 88$, p. 108.

19 P. H. K., I, $\S 86$, p. 108 . Subrayado en el texto. 
el esclarecimiento de ciertas cuestiones básicas como la que aquí acaba de plantear Berkeley es la tarea específica de la filosofía, y no, como se lo proponía el mismo Berkeley, simplemente descubrir absurdos y contradicciones a partir de un axioma semejante al de la identidad de esse y percipi.

Del mismo modo que Berkeley, nos encontramos con esta afirmación de Hume: "supondré, por lo pronto, que sólo hay una única existencia que llamaré indiferentemente objeto o percepción... entendiendo por ambos lo que todo hombre corriente significa por un sombrero, un zapato, una piedra o cualquiera otra impresión que le transmitan sus sentidos". 20 Se trata, como podemos ver, de la misma identidad de un esse particular con un percipi correspondiente sobre la base de que ambos se definen por el mismo conjunto de cualidades-sensibles, pues Hume afirma luego que "no tenemos ninguna idea de una cualidad cualquiera en un objeto que no corresponda, y que no pueda representar, a una cualidad en una impresión; y ello porque todas nuestras ideas se derivan de nuestras impresiones". ${ }^{21}$ Por lo demás, ya hemos visto que para Hume un esse particular es idéntico a una colección de ideas simples, y sólo falta añadir ahora que si esto es así es porque el conjunto de cualidades-sensibles particulares que definen un objeto es idéntico al conjunto de cualidades que definen la idea (compleja) de ese objeto y, por lo tanto, que "formar la idea de un objeto y formar una idea simplemente es la misma cosa". 22

Naturalmente, en el caso que estamos examinando, esse y percipi han dejado de ser "sujetos" de inhesión del conjunto de cualidades-sensibles en que se identifican, y las cualidades-sensibles han dejado de ser también "predicados" de un sujeto distinto de ellas. ${ }^{23}$ En esta virtud, el sentido en que aquí es aplicable el principio de la identidad de los indiscernibles a esse y percipi tiene que ser analitico, pues los términos de la relación de identidad se definen en este caso exacta y exclusivamente por un mismo conjunto de cualidades-sensibles. Mas si esse y percipi se identifican en el mismo conjunto de cualidades-sensibles, sin que esto remita ya a un sujeto específicamente diferente de ese conjunto de cualidades, ¿qué consecuencias se derivan de aquí? En este punto me parece conclusiva una opinión de C. I. Lewis sobre el tema. Lewis distingue también entre el sentido sintético y el sentido analítico en que puede manejarse el principio de la identidad de los indiscernibles, aunque no los llame de esta manera. Establece dos clasificaciones de los objetos que pueden nombrarse: "una de ellas, tal que 'A' y ' $\mathrm{B}$ ' pueden denotar la misma entidad sólo si una persona que observa directamente lo que ' $A$ ' nombra y lo que ' $B$ ' nombra es capaz también de observar que nombran la misma cosa; y la otra, tal que lo que ' $A$ ' nombra puede ser idéntico a

20 Hume, T.H. N., I, iv, 2, p. 253.

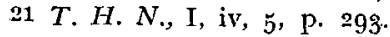

22 T. H. N., I, i, 7, p. 63.

23 Berkeley, P. H. K., \$ 49, p. 88 . Hume, T. H. N., I, i, 6, p. 60; y I, iv, 5, p. $2 \varepsilon_{4}$. 
lo que nombra ' $\mathrm{B}$ ', aun cuando se puede observar lo que ' $\mathrm{A}$ ' nombra y lo que ' $B$ ' nombra sin que sea posible establecer la identificación". ${ }^{24}$ Pero luego señala que los objetos que pertenecen a la segunda clasificación, o son objetos fisicos tales como los considera la ciencia física: electrones, rayos ultravioleta, etc., o son eventos que ocurren en "otras" mentes, objetos siempre improbables desde el punto de vista de su apariencia fenoménica, mientras que los objetos que pertenecen a la primera clasificación son "fenómenos de conciencia", esto es, fenómenos acerca de los cuales no cabe la menor duda con respecto a su identificación. Y, en efecto, parece no haber otra conclusión. Si lo que se significa por "esse" y por "percipi" no es más que un conjunto de cualidades-sensibles que se llaman "XYZ", no es posible entonces que XYZ esté presente directamente y que aún subsista alguna duda respecto a si está presente un esse y un percipi determinado y respecto a si éstos son lo mismo. La duda sobrevendría si por "esse" se significara un objeto que existe independientemente de la percepción, esto es, como se ha entendido hasta ahora, un objeto específicamente distinto de la percepción, de nuestros propios datos sensibles, y no un objeto cuya existencia es independiente de la percepción en el sentido de que su existencia no depende causalmente de que sea percibido, que ésta es otra cuestión. Pero si un esse específicamente distinto de nuestros propios datos sensibles no sólo entraña contradicción, según Berkeley y Hume, sino que implica duda acerca de si es lo mismo que designa el término "percipi", es claro entonces que ambos filósofos han tomado "esse est percipi" como una proposición analítica. Pero dado lo que hemos asentado, la proposición equivale a la afirmación de que cualquier cosa que es o existe es algo "mental" o algo que es "parte" de la mente, específicamente idéntico a lo mental; y si esta identidad específica de esse y percipi se la reduce a la afirmación de que nada existe si no es causalmente dependiente de que sea percibido, es claro también que se estarían confundiendo dos cuestiones muy distintas, pues no es lo mismo preguntar si existe o si podemos conocer algo que no sea "parte" de la mente a preguntar si existe o si podemos conocer algo sin que sea percibido. La pregunta ( $I$ ) "¿podemos conocer algún objeto cuya realidad no sea parte de nuestra mente?" es muy distinta a la pregunta (2) "cpodemos conocer algún objeto aun cuando no lo estemos percibiendo?" Hasta donde hemos visto, Berkeley y Hume habrian confundido esta última pregunta con la primera, ya que ambos consideran que un objeto que existiera cuando la mente o alguna mente no lo estuviera percibiendo sería un objeto "específicamente" distinto de la percepción. Puesto que de ambas cuestiones hacen una misma cuestión por reducción a la primera, y su respuesta es que es imposible conocer un objeto semejante, Berkeley y Hume no logran romper el círculo de los fenómenos de conciencia. Del fenomenalismo

24 C. I. Lewis, "Some Logical Considerations Concerning The Mental", Readings in Philosophical Analysis, New York, Appleton, 1949, pp. 387-988. 
subjetivista por ellos defendido se puede decir lo que llegó a decir Moore de todo idealismo: ahí "el espíritu saluda al espíritu" en su objeto.25

La reducción de la pregunta (2) a la pregunta (1) en los filósofos de que venimos tratando deriva de que ellos entienden por objeto conocido un objeto percibido, de aquí que la pregunta “¿podemos conocer un 'objeto percibido' aun cuando no lo estemos percibiendo? resulte altamente improbable o quizás imposible, como ellos piensan, de contestar afirmativamente. Pero si se mantiene la distinción entre una y otra pregunta y por objeto conocido no se entiende un objeto percibido, exclusivamente, la pregunta (2) toma esta otra versión: ¿podemos conocer algún objeto no percibido (esto es, que no estemos percibiendo) sobre la base de lo que en un momento dado conocemos como objeto percibido? Si esta pregunta es legítima no puede ya confundirse con la pregunta (1), porque en ésta se pregunta por la posibilidad de conocer un objeto cuya realidad no sea parte de la mente, es decir, cuya realidad no consista en ser percipi o ser una experiencia perceptiva, mientras que en la pregunta (2) la cuestión se refiere a si, sobre la base de los objetos que en un momento dado percibimos, podemos conocer objetos causalmente independientes de que sean percibidos, objetos que si bien no son percibidos ni su existencia depende de que sean percibidos pudieran, no obstante, conocerse sobre la base de los "objetos percibidos", y todo ello al margen de si los objetos en cuestión son especificamente distintos o idénticos a una experiencia perceptiva o a una parte de la mente. Esta última cuestión es epistemológica, en tanto que el problema de si los objetos "materiales" que conocemos son en el fondo específicamente idénticos o distintos de la mente es un problema metafísico que ha dado lugar, cuando se ha seguido la vía de la identidad, a diversos idealismos espiritualistas, como el de Leibniz y el del mismo Berkeley, guardadas sus diferencias, o que ha conducido, cuando se ha seguido la vía de la distinción, a dualismos metafísicos como el de Descartes donde los objetos son objetos del espíritu que están en él como atributos suyos o bien son objetos que no están en él de esa manera, sino que son "extramentales", y en general a dualismos metafísicos de las "cosas en si" donde éstas no presentan los caracteres de los objetos percibidos.

Pero al parecer estamos suscitando una nueva cuestión que debe ser abordada a fin de explicar la posición que adoptan Berkeley y Hume. En efecto, nuestra segunda pregunta, a saber, si objetos que no son percibidos y que no dependen causalmente para existir de que sean percibidos pueden, no obstante, conocerse sobre la base de los objetos percibidos, también podría presentarse en forma contraria de esta otra manera: los objetos que conocemos como objetos percibidos ¿los conocemos sobre la base de objetos que no son percibidos?; en otras palabras, los objetos que conocemos como objetos per-

25 G. E. Moore, "The Refutation of Idealism", Philosophical Studies, London, Routledge \&: Kegan Paul, 1965, p. 6. 
cibidos ¿son objetos cuyo conocimiento y cuya naturaleza inclusive son causalmente dependientes de objetos que existen cuando no son percibidos? Nuestra cuestión, por lo tanto, suscita desde este momento un cierto dilema que consideraremos a continuación.

\section{El problema de la teoria causal de la percepción. Un dilema}

El fenomenalismo tentativamente aludido que sustentan Berkeley y Hume resultará aún más delimitable si tomamos en cuenta que estos filósofos representan sendas reacciones ante el problema de la llamada "teoría causal de la percepción" que ahora consideraremos. Recordemos que antes que partir de una definición queremos llegar a una definición de fenomenalismo después de discutir algunas cuestiones.

Según la teoría causal de la percepción, ejemplarmente expuesta por Locke en los tiempos modernos, todo lo que percibimos o conocemos en sí mismo mediante la percepción exterior, todo lo que constituye el objeto inmediato y directo de la percepción exterior, son "ideas de sensación" existentes en la mente. Pero la teoría no se limita a afirmar que el conocimiento, como la naturaleza, de las ideas de sensación es causalmente dependiente de objetos materiales que existen cuando no son percibidos, sino que afirma que el conocimiento y la naturaleza de las ideas de sensación son causalmente dependientes de objetos materiales específicamente distintos de las ideas que producen. De esta manera introduce un dualismo metafísico como el que ya señalábamos, pues la causa del conocimiento y naturaleza de las ideas de sensación se hace residir en objetos "extramentales" en el sentido de ser sustancias reales consistentes en un conjunto de cualidades potenciales "insensibles", inaccesibles a la percepción directa $y$, en esa medida, directamente incognoscibles. ${ }^{26}$ En este dualismo, si solamente podemos conocer directamente las ideas y no los objetos mismos que las producen ¿cómo podemos justificar, a pesar de todo, que esos objetos no sólo existen, sino que tenemos algún conocimiento de ellos? Locke mismo advirtió esta dificultad en el Cuarto Libro del Ensayo, sin que al parecer la hubiese resuelto.

Declara al respecto: "Es evidente que la mente no conoce de un modo inmediato las cosas, sino únicamente por la intervención de las ideas que tiene de ellas. Por eso, nuestro conocimiento sólo es real en la medida en que existe una conformidad entre nuestras ideas y la realidad de las cosas. Pero ¿cuál ha de ser aquí el criterio? ¿Cómo ha de conocer la mente, puesto que no percibe sino sus propias ideas, que éstas están de acuerdo con las

26 J. Locke, An Essay Concerning Human Understanding, London, Everyman's Library, 1959, II, viii, §§ 7-8, pp. 44-45- (Trad. española, FCE, pp. 112-113.) Cf. III, vi, § 9, p. 227; (trad. esp., pp. $435-43^{6}$ ). 
cosas mismas?" 27 Y Locke, apremiado por la dificultad, aun habiendo establecido antes que ideas simples como las de blancura, frialdad, etc., no guardan la menor semejanza con las cualidades reales de los cuerpos y que esas ideas no están más en estas cualidades que la enfermedad o el dolor en el azúcar que los produce, ${ }^{28}$ resuelve a continuación el problema afirmando que "la idea de blancura, o de amargor, tal como está en la mente, respondiendo con exactitud a esa potencia que existe en cualquier cuerpo para producirla en la mente, tiene toda la conformidad real que pueda o que deba tener con las cosas fuera de nosotros".29 Pero esto no es propiamente una solución; es simplemente la afirmación de un hecho por cuya justificación se preguntaba y no la justificación misma. La duplicidad del mundo que se postula, al sostenerse que además y detrás de lo que percibimos inmediatamente existe un mundo de "objetos exteriores" inaccesible a la percepción que es causa de lo que percibimos, queda postulada sin justificación puesto que si este mundo de objetos exteriores es inaccesible a la percepción, es igualmente inaccesible o incognoscible que sea causa de lo que percibimos inmediatamente. Por lo demás, el propio Locke declara que entre las ideas de sensación y la constitución real de los cuerpos en "partículas insensibles", de la que aquéllas dependen causalmente, "there is no discoverable connection... there is no conceivable connection". 30

En esas condiciones, habiéndose postulado semejante duplicación del mundo sin justificar la relación cognoscitiva que ella planteaba, repetimos, por un lado el dominio de las ideas de sensación que nos son directamente conocidas y por otro lado un dominio de objetos materiales distintos de aquéllas y causa de aparición, pero sin que se explique entonces cómo podemos conocer tales objetos materiales que incluso son causa de lo que percibimos inmediatamente, no faltaban razones a Berkeley para objetar el dualismo característico de la interpretación causal de la percepción cuando insistía en el escepticismo con que ésta se acompaña regularmente. ${ }^{31}$ Aunque podría preguntarse, ¿no admitimos siempre, hasta por inclinación natural, que todas nuestras ideas de sensación, o si se prefiere, todos los "datos sensibles" que tenemos con ocasión de percibir un objeto material, tales como las experiencias perceptivas que tenemos de un color, una figura, un volumen, un sonido,

27 Op. cit., IV, iv, § 3, p. 273; (trad. esp., p. 562). Problema insoluble dentro del planteamiento de Berkeley; cf. la cita referida en la anterior nota 19.

28 Op. cit., II, viii, $\$ \$ 15$ y 17, pp. $47^{-48}$ (trad. esp., pp. 115-116).

29 Op. cit. IV, iv, $\$ 4$, p. 273 (trad. esp., p. $5^{63}$ ).

30 Op. cit., IV, iii, \$\$ 12-13, p. 264 (trad. esp., pp. 543-544).

31 Una interpretación no dualista de la epistemología de Locke puede verse en: M. Mandelbaum, Philosophy, Science, and Sense Perception, Baltimore, The Johns Hopkins Press, 1966, I, iv, p. $4^{6} \mathrm{ss}$. Mandelbaum sostiene que no hay tal dualismo ni tal escepticismo en Locke, porque éste facilita el camino para que nuestro conocimiento ordinario de los objetos materiales sea tratado como un conocimiento "continuo con aquel análisis más refinado de estos objetos que puede lograrse por investigadores experimentales" (p. $5^{6}$ ). 
un sabor, o una sensación táctil, están causalmente conectadas con objetos exteriores? Pero ya Hume advertía que si admitimos o creemos en esta conexión no es sino porque en el espiritu se dan relaciones de sucesión, contigüidad, constancia, y semejanza, entre las "percepciones" y que, por consiguiente, la conexión causal de éstas con un objeto exterior es sólo una inferencia ficticia producto de la imaginación. Claro está que la explicación de Hume es una explicación pșicológica; nos dice cómo llegamos a creer en la conexión causal de referencia, mas nada nos dice acerca de si habría razones lógicas que justifiquen la creencia de que los datos sensibles. están conectados causalmente con objetos exteriores. Después de lo que ya hemos dicho, es obvio que ni Hume ni Berkeley podían pretender este tipo de justificación, ya que rechazaban abiertamente que pudieran darse razones lógicas que justificaran la existencia y el conocimiento de objetos exteriores que sean causa de "lo que percibimos". Si es así es porque ellos no reconocen sobre este tema otra razón lógica que la de la identidad e indiscernibilidad de esse y percipi. Por este motivo ambos podrían haber coincidido con Locke en que, entre lo que percibimos y lo que se postula como su causa, "no hay ninguna conexión descubrible... ninguna conexión concebible". De qué lado descansa, en este punto, lo que para ellos es racionalmente concebible, se ve con claridad ahí donde Berkeley reitera que el enunciado de que existen objetos distintos de la percepción de ellos que son causa de ésta es tan contradictorio como el enunciado de que objetos que son percibidos no tienen, al mismo tiempo, existencia real; o bien ahí donde Hume sostiene que la opinión de quienes piensan que las percepciones son representaciones conectadas causalmente con objetos exteriores distintos de ellas, es una opinión que, "si se la hace descansar en el instinto natural, es contraria a la razón, y si se la refiere a la razón, es contraria al instinto natural'. 32

Las dudas suscitadas por el dualismo de la teoría causal de la percepción explican mejor ahora el giro que tomó con Berkeley y Hume la teoría de la percepción. Ya no se trata de distinguir entre el dominio de lo que percibimos directamente, asimilable en todo caso a ideas de sensación, y una región de objetos materiales insensibles que son causas de lo que percibimos, sino de identificar el objeto material con "lo que percibimos", y de negar ya la existencia o ya el conocimiento de aquello que en el dualismo de la teoría causal de la percepción se entiende por "objeto material". No se trata más de que lo que percibimos sea una cifra que remite a un objeto material que la cifra por sí misma no hace manifiesto, ni de que el objeto material sea un escondrijo inaccesible desde el cual se produce lo que percibimos. Por el contrario, lo que se da en llamar "objeto material" no es más que un conjunto de ideas de sensación, lo único que percibimos de un

32 D. Hume, An Enquiry Concerning Human Understanding, Oxford, ed. Selby-Bigge, 1961, Parte I, Sección XII, p. 155. 
modo inmediato. Mas en este caso no puede significarse ya por "objeto material" la causa remota de lo que percibimos, sino únicamente aquello que se reduce a un conjunto de datos sensibles.

En esta dirección se orientan las palabras de Filonus cuando sostiene que si los objetos inmediatos de la percepción son $(\Rightarrow$ ideas, y las cualidades sensibles son $\Leftrightarrow$ objetos inmediatos de la percepción, entonces (puesto que en esa virtud las cualidades sensibles se identifican con las ideas) es preciso negar que exista algún substratum imperceptible de los objetos sensibles y que exista, en ese sentido (in that acceptation), sustancia material alguna; pero que si por sustancia material se significa solamente el cuerpo sensible, lo que se ve y lo que se siente (that which is seen and felt), entonces es más segura la existencia de lo que él significa por "materia" que lo que otros filósofos entienden por esa palabra. Que se diga, en fin, que él niega la realidad de los objetos sensibles, eso no es sino una falsa interpretación (misapprehension), es decir, una confusión del sentido en que algunos hablan del objeto material en términos de esencias filosóficas (philosophical quiddities) con el sentido en que él habla del objeto material. ${ }^{33}$ Ahora bien, a la misma concepción llegó Hume, pues, como vimos anteriormente, tampoco para él hay más sustancia material que la que se reduce a una colección de cualidades sensibles o de ideas simples.

Debemos señalar ahora que el giro que tomó con Berkeley y Hume el sentido en que debía entenderse el llamado "objeto material", frente al sentido que esta designación tiene dentro de la teoría causal de la percepción, no representa sino un enfrentamiento ante un falso dilema: el dilema entre la concepción científico-causal y la concepción ordinaria del mundo. Puesto que ambas concepciones se sitúan en el terreno mismo de la ontología, la disputa se presenta como un conflicto por el derecho de ocuparlo, en un sentido o en otro, con exclusión del contrario. Si el mundo descrito por la ciencia difiere del mundo que describe el sentido común por el cual Berkeley y Hume pretenden responder, y si, por otra parte, no existe más que un mundo, alguno de esos mundos descritos ha de ser ficticio. Cuando el mundo de los objetos que cabe llamar, con más propiedad, objetos "reales" se hace descansar en entidades de las que no se puede dar cuenta mediante los datos que nos proporciona ordinariamente la percepción directa de las cosas o que ésta podria proporcionarnos, entonces el mundo "percibido" en que se apoya la concepción común de la existencia de objetos reales resulta, al contrario, un mundo "irreal" o que tiene a lo sumo existencia real sólo como experiencia perceptiva, como conciencia perceptiva, pero que en rigor no constituye un "mundo exterior"; este razonamiento es el que se sustenta por lo general en la ciencia física. Pero cuando se piensa, por la parte opues-

33 Berkeley, Three Dialogues Between Hylas and Philonous, editados con los Principles en Fontana Library, tercer diálogo, pp. 228-229. 
ta, que no hay más mundo de objetos reales ni más mundo exterior que el que se reduce y sólo puede explicarse en términos de lo que ordinariamente o bien es percibido, o bien es "perceptible", entonces el que resulta irreal o quizás una "ficción teórica" es el mundo de las entidades insensibles cuya "naturaleza interior" - como llega a sostener incluso un reconocido crítico del fenomenalismo- hay que "imaginarla" como un depósito de "propiedades disposicionales imperceptibles". ${ }^{34}$

$\mathrm{La}$ falsedad de este dilema, según Ryle, estriba en que se considere que la concepción científica del mundo y la concepción del mundo que el hombre ordinario se forma a partir de la base de la experiencia directa de las cosas son dos respuestas antagónicas acerca de una misma cuestión, cuando en verdad ambas concepciones son tan sólo dos áreas diferentes del lenguaje que responden a cuestiones diferentes, aunque referidas a un mismo mundo. Así como de la descripción que hace de una biblioteca un estudiante de historia o de filosofía y de la descripción que hace de esa misma biblioteca un tenedor de libros no pueden resultar "dos bibliotecas antagónicas" o "dos descripciones antagónicas de una biblioteca", sino únicamente "dos maneras diferentes, pero complementarias, de dar información de especies muy distintas acerca de la misma biblioteca", asimismo la concepción del mundo del físico nuclear y la concepción ordinaria del mundo que se apoya en la experiencia directa de las cosas no tienen por qué conducir a dos mundos antagónicos sino, a lo más, a dos imágenes "muy diferentes, y con todo, compatibles y aun complementarias de uno y el mismo 'mundo" ". 35

En relación con el dilema a que hemos aludido y después de lo que acabamos de exponer, nos parecec importante observar que lo que hace Ryle en realidad es mostrar que tal dilema no tiene razón de ser porque las dos formas diferentes de lenguaje en cuestión tienen derecho para legislar con igual validez dentro de sus respectivas esferas de información, pero no porque ambas formas de lenguaje sean compatibles, como también lo supone Ryle. Es decir, el dilema es falso porque tanto el lenguaje de la ciencia física como el lenguaje ordinario pueden establecer, con toda independencia, las condiciones en que uno y otro se refieren a objetos reales, pero no porque no subsista ninguna discrepancia entre los objetos a que se refieren. En efecto, cuando el lenguaje de la ciencia física se refiere a objetos reales en el sentido de ser entidades que no pueden explicarse por lo que es directamente percibido, y cuando el lenguaje ordinario se refiere a objetos reales sólo en el sentido de lo que es directamente percibido o perceptible, ${ }^{36}$

34 C. D. Broad, "The 'nature' of a Continuant", Readings in Philosophical Analysis, ed. cit., pp. $47^{2}$ ss.

35 G. Ryle, Dilemmas, Cambridge University Press, 1966, V, pp. 78-80.

36 De momento no discutiremos mayormente si "lo directamente percibido" se refiere a la experiencia perceptiva o si se refiere a algo exterior y distinto de ella, y si aun refiriéndose a algo exterior y distinto de la experiencia perceptiva eso a que se refiere es o 
el conflicto entre ambos queda neutralizado tan pronto como uno y otro lenguaje dejan de usarse para dirimir, en subrogación del contrario, una misma cuestión: qué es y cómo conocemos la realidad. Pero la solución del conflicto, de esa manera, no lleva a una conciliación entre las imágenes (pictures) que ambos lenguajes producen. Aunque Ryle habla de compatibilidad, él habría suprimido el conflicto no mediante una compatibilidad, sino mediante un mero paralelismo entre ambos lenguajes. Dice, por ejemplo: "una afirmación que es verdadera o falsa respecto de uno, no es $n i$ verdadera $n i$ falsa respecto del otro. No puede ser, por lo tanto, opuesta respecto de este otro". ${ }^{37}$ Con esto, insistimos, si bien queda neutralizado el conflicto entre el lenguaje de la ciencia física y el lenguaje ordinario, no se logra establecer su compatibilidad, su intercomunicación $y$, en últmo término, su traducibilidad. Porque, ¿qué significa que dos lenguajes diferentes sean compatibles aparte de significar que entre ambos es posible la comunicación y que uno es de algún modo traducible al otro? Pudiera ser que por compatibilidad entre dos lenguajes informativos diferentes se entendiera una simple coexistencia pacífica de "dos verdades", y pensamos que esto es en definitiva lo que entiende y nos propone Ryle. Pero el asunto es más complicado; porque, tal como lo presenta R.yle, no se trata sólo de que la verdad o la falsedad de las afirmaciones que se hacen en un lenguaje sean independientes -no antagónicas - de la verdad y la falsedad de las afirmaciones que se hacen en el otro, sino también de que tanto el lenguaje de la ciencia física como el lenguaje ordinario son lenguajes informativos, lenguajes-objeto. Se trata también, por consiguiente, de que asi como no hay ninguna conexión manifiesta entre las áreas de objetos a que se refieren ambos lenguajes, tampoco entre éstos hay, como lenguajes-objeto, ninguna comunicación. En otras palabras, las imágenes del mundo a que dan lugar ambos lenguajes se excluyen recíprocamente, son incompatibles, aunque esto no pueda decirse de la verdad o falsedad de sus respectivas afirmaciones. $Y$ aquí, precisamente, podemos preguntarnos si Ryle ha resuelto del todo o eliminado el dilema que nos viene ocupando. Porque el dualismo resulta ahora por partida doble. En efecto, si se lo considera desde el punto de vista de la verdad o falsedad de las afirmaciones que se hacen en uno y otro lenguaje, el resultado es únicamente una falta de entendimiento común, un paralelismo de dos verdades. Pero si se lo considera desde el punto de vista de las imágenes del mundo que ambos lenguajes generan, el dualismo del lenguaje-objeto nos devuelve al mismo problema a que nos enfrenta la teoría causal de la percepción: los objetos físicos no se reducen ni se explican por los objetos percibidos y, por lo tanto, como expresaba Locke, no

no "parte" de un objeto físico. Todos estos aspectos son tan atractivos que fácilmente pueden devolvernos al dilema que ahora estamos presentando en su generalidad.

37 G. Ryle, op. cit., V, p. 79 . 
hay entre ellos ninguna conexión descubrible. Consideremos, por ejemplo, las siguientes proposiciones:

1) Hay aquí realmente una mesa (proposición que abreviaremos por $P_{1}$ y el lenguaje-objeto a que pertenece por $L_{1}$ );

2) Hay aquí realmente un conjunto de partículas insensibles (que abreviaremos por $\mathrm{P}_{2}$ y el lenguaje-objeto a que pertenece por $\mathrm{L}_{2}$ ).

Partiendo del supuesto de que estas proposiciones tienen maneras distintas de probar su verdad o su falsedad, podemos decir, entonces, que si $P_{1}$ es verdadera o falsa en $L_{1}$, no tiene por qué ser ni verdadera ni falsa en $L_{2}$. $Y$ viceversa, si $P_{2}$ es verdadera o falsa en $L_{2}$, no tiene por qué ser ni verdadera ni falsa en $L_{1}$. Lo cual significa que $P_{1}$ y $P_{2}$ pueden ser verdaderas al mismo tiempo sin entrar en conflicto, porque si la verdad de $P_{1}$ es independiente $o$ distinta de la verdad de $P_{2}$, no podemos decir que aunque $P_{1}$ у $\mathrm{P}_{2}$ se refieren a objetos incompatibles son verdaderas en el mismo sentido. Por consiguiente, $P_{1}$ y $P_{2}$ pueden ser verdaderas al mismo tiempo en $L_{1}$ y en $L_{2}$ respectivamente. Ahora bien, ipodría sostenerse, a pesar de todo, que si $P_{1}$ es verdadera en $L_{1}$ por eso mismo no es verdadera (es falsa) en $L_{2}$ ? Pero "es verdadera en $L_{1}$ " y "no es verdadera (es falsa) en $L_{2}$ " no pueden afirmarse al mismo tiempo de $P_{1}$. Uno y otro predicado pertenecen a lenguajes-objeto diferentes. Si los afirmáramos a la vez estaríamos recayendo en el conflicto por legislar sobre una misma área de objetos. Posteriormente veremos que si la cuestión se plantea no al nivel del lenguaje-objeto, o en el modo "material" de hablar, sino al nivel de un lenguaje en que sólo se mencionan expresiones o "designaciones" de objetos - en el modo "formal" de hablar-, es posible que una misma "oración" sea verdadera en un lenguaje "formal" $L_{1}$ y que al mismo tiempo no sea verdadera en otro lenguaje formal $\mathrm{L}_{2}$; porque en este caso ya no se trata de dos conceptos absolutos de verdad, sino de un concepto semántico de verdad. En este caso, oraciones como " $\mathrm{O}_{1}$ es verdadera en $\mathrm{L}_{1}$ " y " $\mathrm{O}_{1}$ no es verdadera en $\mathrm{L}_{2}$ " pueden ser ambas verdaderas sin suscitar conflicto alguno, mientras "verdad" y "falsedad" conservan un mismo sentido semántico. ${ }^{38}$

Pero la solución que ofrece Ryle al dilema no es concluyente, porque los lenguajes-objeto dentro de los cuales se lo intenta resolver continúan manteniendo una incompatibilidad entre los objetos a que remiten las imágenes del mundo que en ellos se producen. En efecto, por el lado de las proposiciones, $\mathrm{P}_{1}$ y $\mathrm{P}_{2}$ pueden admitirse como verdaderas al mismo tiempo sin conflicto; mas las imágenes del mundo a que dan lugar son ontológicamente incompatibles. Desde este último punto de vista, es difícil admitir que una misma porción del espacio esté ocupada por una mesa y sólo por una mesa

3s Arthur Pap, "Note on the 'semantic' and the 'absolute' Concept of Truth", Philosophical Studies, vol. III, No $1,195^{2}$, p. 2. Artículo crítico sobre la concepción semántica de la verdad en Carnap. 
-lo que significa, ordinariamente, por un cuerpo sólido, continuo, de una cierta figura y un cierto color y extensión- y que al mismo tiempo esté ocupada solamente por un conjunto de partículas insensibles, volátiles, discontinuas, incoloras y sin figura. Esta dificultad, decimos, nos devuelve al dilema, pues equivale a la dificultad que se presenta entre quien afirma que el mundo físico se reduce a datos sensibles y quien afirma que se reduce a entidades materiales, pero insensibles, con la pretensión de que ambas tesis sean ontológicamente valederas. Pero como hemos ya establecido, ambos miembros de esta dificultad generan, a su vez, una dificultad más por cada una de las partes. La primera tesis reduccionista, cuando por objetos a datos sensibles se entiende sólo "ideas de sensación", conduce a la imposibilidad de afirmar que existe un "mundo exterior", según quedó claro en el parágrafo anterior. El reduccionismo de la segunda tesis, cuando hace del mundo físico la "causa" de lo que percibimos, no alcanza a explicar, como teoria de la percepción, ni el nexo causal ni que el mundo físico sea causa de lo que percibimos, según hemos visto en el presente parágrafo.

Insistimos ahora en esta última dificultad, porque ella explica mejor el giro que a su raíz tomó la teoría del conocimiento de Berkeley y la de Hume, teoría que en ellos coincide con una teoría de la percepción. Ambos filósofos, podemos resumir ahora, ante la ruptura con el mundo inmediato de "lo percibido" que introduce la teoría causal de la percepción, ante el dilema entre la concepción científico-causal y la concepción ordinaria del mundo, formularon una interpretación fenomenalista del objeto material al reducirlo a una mera collection de ideas de sensación. Berkeley es más taxativo ante el dilema; sin la menor vacilación, simplemente rechaza por absurda e inexplicable la tesis de existencia de cosas que sean causa de lo que percibimos. $^{39}$ En Hume, en cambio, nos encontramos con la conciencia clara y el acogimiento pleno del dilema. De un modo conciso, pero punzante, lo expresa de esta manera: "cuando razonamos a partir de la causa y el efecto, concluimos que ni el color, el sonido, el sabor, ni el olor, tienen una existencia continua e independiente. Cuando excluimos estas cualidades sensibles, no queda nada en el universo que tenga tal existencia".40 Por el contexto en que lo expresa, el dilema es el que plantea una situación en la que, por una parte, se afirma que existen, independientemente de las cualidades sensibles, causas reales de lo que percibimos y en la que por ello se niega la existencia real e independiente de lo que percibimos, pero en la que, por otra parte, y al mismo tiempo, esta última negación implica la negación de lo mismo que se afirma como causa real de lo que percibimos. Lo cual pone de manifiesto que, o sólo existen realmente las causas exteriores de lo que percibimos, pero no lo que percibimos, o sólo existe realmente lo que per-

40 Hume, $T . H . N ., \mathrm{I}$, iv, 4 , pp. $281-282$ (al final de la Sección). Subrayado mio. 
cibimos (pues su negación no deja más en pie ninguna existencia real); pero no ambas cosas a la vez.

Debemos agregar unas últimas consideraciones sobre esta cuestión. En primer lugar, ¿por qué toma Hume tan en serio este dilema ahora, si ya en la sección VI de la Segunda Parte, Primer.Libro, del Treatise había establecido, tan categóricamente como Berkeley, que no hay más existencia que la que se identifica con las percepciones, que es imposible concebir la existencia de un objeto distinto de las percepciones? Hay que hacer aquí una restricción. En aquella sección se trataba de saber, principalmente, si podía concebirse la existencia de un "objeto exterior" entendiendo por éste un objeto "especificamente diferente" de las percepciones; además, el problema se planteaba en la forma de un dilema distinto, a saber, "que como nunca tenemos presente. idea o impresión. alguna sin atribuirle existencia, o la idea de existencia tiene que derivarse de una impresión diferente, asociada a toda percepción u objeto de nuestro pensamiento, o tiene que ser exactamente lo mismo que la idea de la percepción u objeto". ${ }^{41}$ Como vimos en el parágrafo anterior, esa especie de existencia exterior, según Hume, es imposible, y el dilema correspondiente se destruye tan pronto como se identifican la idea de existencia, la idea de objeto y la de percepción.

Pero ahora se trata de saber si puede concebirse la existencia de un "objeto exterior" entendiendo por éste ya no un objeto específicamente diferente de la percepción, sino un objeto que existe cuando no se lo percibe, que es causalmente independiente de la percepción, cuya existencia, en suma, es continua, exterior e independiente, en el sentido de que no necesita para existir que sea percibido. Pues bien, de esta especie de existencia exterior es de la que se ocupa Hume en la Cuarta Parte (especialmente en la sección II), Libro Primero, del Treatise, y a propósito de ella se plantea el presente dilema, porque - dice Hume- "por lo que tóca a la noción de existencia exterior, cuando se toma por algo especificamente diferente de nuestras percepciones, ya hemos mostrado su absurdo".42 En otras palabras, la forma de existencia exterior que ahora se tiene en cuenta es la del objeto idéntico consigo mismo, continuo e inalterable, que persiste independientemente de las percepciones cambiantes y discontinuas; algo aparentemente tan simple e innocuo como la afirmación de que un objeto físico continúa existiendo cuando dejo de percibirlo, en ausencia de toda percepción o en el intervalo de dos actos perceptivos, pero acerca de lo cual nada es más difícil que aclarar el sentido que tenga esa afirmación. Ahora bien, sobre esta forma de existencia y el dilema que ella plantea, Hume concluye en definitiva lo siguiente: puesto que en rigor y por principio sólo nos es conocido lo que percibimos, o afirmamos que el objeto exterior y continuo existe y nos es 
conocido, y en este caso afirmamos una contradicción, pues equivale a afirmar que "los sentidos continúan operando aun después de que en ellos ha cesado toda forma de operación", +3 o afirmamos que existe, pero que nos es desconocido, y en este otro caso, por mucha que sea la semejanza y constancia que encontremos en nuestras percepciones, no encontramos en éstas toda la constancia o continuidad que conferimos (bestow) al objeto exterior, como no sea imaginando que, a pesar de la inconstancia y discontinuidad que les es propia, continúan "unidas por algo acerca de lo cual no tenemos percepción". ${ }^{44}$ Por consiguiente, la afirmación de que existen objetos exteriores de la especie que estamos considerando sólo tiene sentido, según Hume, si por ella se entiende que los objetos en cuestión son objetos imaginarios en los cuales podemos creer, pero no objetos de conocimiento.

Después de esto, y como resultado de las posiciones adoptadas ante el dualismo y el dilema a que conduce finalmente la teoría causal de la percepción, podemos no sólo delimitar todavía mejor lo que deba entenderse por una doctrina fenomenalista como la que representan Berkeley y Hume, sino también sus matices. En efecto, si por fenomenalismo se entiende una doctrina filosófica en la que se sostiene que no podemos conocer, ni creer y ni siquiera imaginar, que existen "objetos exteriores", esto es, objetos que no se dan en la percepción ni se explican en términos de "lo que es percibido", entonces, por lo que acabamos de ver, Hume no es un fenomenalista, o a lo menos el fenomenalismo que podría atribuírsele es menos radical que el que Berkeley representa, porque, entendido de esa manera, el fenomenalismo resulta una forma de "escepticismo excesivo" que Hume rechaza. ${ }^{45}$ Pero si por fenomenalismo se entiende una doctrina filosófica que se limita a sostener que sólo podemos conocer objetos en tanto que éstos se reducen a lo que es percibido, pero que hace valer la misma proposición tanto para el conocimiento de objetos "materiales" como para el conocimiento de objetos "espirituales", entonces el fenomenalismo de Hume es más radical que el de Berkeley, pues en este último no se da la tentativa de hacer del espíritu objeto de la percepción. Formuladas de esta manera las

43 Ibid.

44 Ibid., pp. 248-249. Berkeley, como se recordará, no admite más "existencia exterior", en el sentido que aquí nos ocupa, que la que puede concederse a un objeto, primero, o porque "otro" espíritu finito lo percibe cuando "yo" no lo percibo, y segundo, o porque, no teniendo su origen en ningún espíritu finito, tiene su causa en un espíritu infinito $(P . H . K .$, I, $\$ 90)$. Lo primero, sin embargo, no resuelve con universalidad que el objeto sea o tenga existencia exterior, porque siempre será algún espíritu individual el que lo perciba, de modo que valdría también decir que el objeto tiene existencia exterior cuando, si "otros" no lo perciben, "yo" lo percibo. Lo segundo, por otra parte, equivale al mismo problema que plantea la teoría causal de la percepción: lo que percibimos tiene existencia exterior, o bien "pertenece" a un objeto exterior, porque su causa se remonta más allá del campo percibido.

45 Cf., D. Hume, An Enquiry Concerning Human Understanding, ed. cit., Sección XII, Parte II, p. 159 . 
posiciones de Berkeley y de Hume ¿qué resultados positivos podemos contemplar desde ellas? Hasta ahora, por lo que hemos visto, ninguno. Porque, desde el punto de vista de que ambos filósofos parten, o postulamos y afirmamos que podemos conocer que existen objetos exteriores, en el sentido en que hemos insistido particularmente en el presente parágrafo, y en este caso nos vemos envueltos en contradicciones, o suprimimos estas contradicciones, y en este otro caso, debido a la perspectiva egocéntrica en que se plantea la identidad entre esse y percipi, no queda existencia alguna de objetos exteriores, como quedó claro en nuestro primer parágrafo. Lo cual significa que si ellos no se consideraban envueltos en el dilema aquí señalado, de hecho sus posiciones lo hacían más incisivo. De aquí la reformulación del fenomenalismo a que ahora nos referiremos.

\section{Fenomenalismo material y fenomenalismo formal}

Siguiendo un uso ya establecido, ${ }^{46}$ y con el objeto de ubicar algunos problemas a que luego nos referiremos, llamaremos al fenomenalismo representado por Berkeley y Hume fenomenalismo material para hacer notar que su formulación pertenece al "modo material de hablar" y no al "modo formal de hablar", en el sentido que da Carnap a estas dos maneras de formular las aseveraciones filosóficas. Conviene a nuestro propósito poner por vía de ejemplo las dos oraciones siguientes, en las que hasta ahora parecen descansar las dos alternativas del dilema que ya hemos planteado sin haber conseguido su eliminación:

a) una cosa es un complejo de datos sensibles (sensaciones o sensopercepciones);

b) una cosa es un complejo de átomos (partículas o entidades insensibles).

Ahora bien, según Carnap, estas dos oraciones estarán formuladas en el modo material de hablar si ambas afirman de un objeto una propiedad que posee, "en correlación con ella, otra propiedad de carácter sintáctico, es decir, si [en ambas oraciones] hay una propiedad sintáctica que pertenece a una designación de un objeto cuando, y sólo cuando, la propiedad original pertenece al objeto". 47 El caso es que ambas oraciones cumplen con este criterio y están formuladas por eso en el modo material de hablar. En efecto, en las dos oraciones aparecen mencionadas propiedades de objeto tales como "ser una cosa", "ser un complejo de datos sensibles", "ser un complejo de átomos", para todas las cuales se hallan paralelamente las propiedades sintácticas de "ser una designación de cosa", "ser una clase de designaciones de datos sen-

46 Cf., Paul Marhenke, "Phenomenalism", Philosophical Analysis, A Collection of Essays, Prentice-Hall, Inc., Englewood Cliffs, N. J., 1963, pp. 280 ss.

47 R. Carnap, The Logical Syntax of Language, London, Routledge \& Kegan Paul, $1967, V, \S 74$, p. 287 . Subrayado mío. 
sibles", "ser una clase de funciones físicas y de coordenadas espacio-temparales". De modo que formuladas completa y explícitamente, las oraciones a) y b) pueden traducirse al modo formal de hablar, esto es, en términos exclusivamente sintácticos, respectivamente, de la manera siguiente:

$\left.a^{\prime}\right)$ toda oración en que aparece una designación-de-cosa es equipolente con una clase de oraciones en que no aparecen designaciones-de-cosas, sino designaciones-de-datos-sensibles.

$\left.b^{\prime}\right)$ toda oración en que aparece una designación-de-cosa es equipolente con una oración en que aparecen coordenadas espacio-temporales y ciertos functores descriptivos (de la física). ${ }^{48}$

La circunstancia de que en el modo material de hablar, tal como en el que aparecen formuladas las oraciones $a$ ) y $b$ ), se presenta en forma paralela a una propiedad de cosa una propiedad sintáctica que sólo puede pertenecer a una expresión de un cierto lenguaje, induce con frecuencia a pensar que oraciones como $a$ ) y $b$ ) tratan de objetos extra-lingüísticos o que versan acerca de la esencia de las cosas -dando lugar así a "cuestiones disputadas" sin solución como la que hemos considerado a propósito del dilema que a esta altura ya nos es familiar-, cuando en realidad sólo se refieren a expresiones de un cierto lenguaje, a un cierto modo de hablar; de aquí que Carnap llame a estas oraciones "oraciones-de-pseudo-objeto".

Lo anterior significaría que el dilema que se plantea cuando las oraciones $a$ ) y b) se ofrecen en el modo material de hablar como dos alternativas igualmente insostenibles, queda zanjado o "refutado" tan pronto como esas oraciones se traducen al modo formal de hablar en las oraciones $a^{\prime}$ ) y $b^{\prime}$ ). En efecto, de estas últimas oraciones no podemos decir ya que son verdaderas a la vez y compatibles entre sí en virtud de un mero deslinde de cosas o por referencia a dos conceptos absolutos de verdad, como se nos presentaba en la solución de Ryle; porque todo esto no viene al caso ahora. Lo que podemos decir de las oraciones $a^{\prime}$ ) y $b^{\prime}$ ) es que la oración $a^{\prime}$ ) es verdadera por referencia a un lenguaje formal $L_{1}$ y que la oración $b^{\prime}$ ) es verdadera por referencia a un lenguaje formal $\mathrm{L}_{2}$; y que ambas son verdaderas a la vez $y$ compatibles entre sí en relación con un concepto único, formal o semántico, de verdad. En otros términos, las oraciones $a^{\prime}$ ) y $b^{\prime}$ ) son ambas verdaderas sin contradicción porque permiten que, al nivel de "oraciones-de-cosas", se realicen transformaciones de estas oraciones en otra oración o clase de oraciones con las cuales son equipolentes por tener el mismo "sentido aseverativo". 49

48 Ibid., $\$ 78$, p. 301.

$49 \mathrm{Ibid}$. Por dos oraciones equipolentes Carnap entiende aquel par de oraciones que tienen el mismo sentido o contenido lógico, pero de carácter aseverativo, factual (por eso no son formalmente analíticas), y no un par de oraciones por las cuales se entiende psicológicamente lo mismo; pero si tienen el mismo contenido lógico-aseverativo cualquiera de ellas es una consecuencia de la otra (op. cit., § 14, p. 42). 
En contraste con estó, muchas sentencias filosóficas, que debieran ser referidas al lenguaje de las sentencias filosóficas y que en realidad sólo son "sentencias sintácticas" que aluden a ciertas formas de expresión, se presentan en el modo material de hablar como si estuvieran aseverando algo acerca de un objeto (tal como ocurre, por otra parte, en las sentencias de las ciencias positivas y en cualquier sentencia empírica de objeto), cuando, como acabamos de decir, sólo se refieren a determinadas propiedades sintácticas de las expresiones del lenguaje respectivo. Son sentencias sintácticas disfrazadas de sentencias de objeto. Recordemos por un momento la sentencia $u$ oración citada anteriormente: a) una cosa es un complejo de datos sensibles. Esta oración parecé estarse refiriendo a una cosa, y si se la toma en su generalidad, a la esencia de las cosas; parece, además, estar ofreciendo el mismo tipo de información que ofrece esta otra oración: un trozo de tela es un complejo de hilos. Pero comparemos ahora las situaciones. Podemos decir, sin mayor dificultad, que los hilos son miembros o partes constitutivas del complejo que llamamos "tela". Pero ¿podemos decir también, sin mayor dificultad, que los datos sensibles son miembros o partes constitutivas de una cosa u objeto físico? Por el contrario, éste ha sido el mayor problema que haya suscitado la tesis de que una cosa es un complejo de datos sensibles. En efecto, si la figura, el tamaño, el color, etc., que percibo cuando veo una mesa, cambian con las condiciones, las distancias y las perspectivas desde donde la veo, no se ve cómo tantas figuras, tamaños y colores, puedan ser partes constitutivas de una misma mesa. Por otra parte, todos los hilos que constituyen la tela están ahí donde está la tela, mientras que no hay nada más oscuro que afirmar que si ahí está dada una cosa, están dados con ello todos los datos sensibles que la constituyen. A menos que afirmemos que entre todos los datos sensibles de referencia se encuentran incluidos datos sensibles posibles, lo cual en nada remedia la situación, pues un dato sensible posible, como ya veía Hume, entraña contradicción, o por lo menos nos deja ante el "problema de los datos sensibles no percibidos". Posteriormente señalaremos, aunque sea brevemente, si estas ambigüedades se resuelven a satisfacción cuando la tesis enunciada en la oración a) se traduce al modo formal de hablar en la oración $a^{\prime}$ ).

Sólo para insistir en este género de confusiones a que conduce el modo material de hablar aludiremos ahora un par de ejemplos. Uno nos lo brinda Berkeley. Se trata de eludir una consecuencia al párecer inevitable en la doctrina de Berkeley. Sostiene éste que aunque las cualidades sensibles, tales como la extensión, el color, la figura, sólo existen en la mente, de aquí no se sigue que la mente sea extensa, que tenga un color y una figura, argumentando para el caso que "esas cualidades están en la mente sólo como ésta las percibe - esto es, no como modo o atributo, sino sólo como 
idea".50 El problema que esto plantea es que, por una parte y según el mismo Berkeley, todas estas cualidades, si son reales, están al mismo tiempo en la mente (y bajo este aspecto serían qualia sensibles, sensaciones o ideas de sensación) y en el objeto (bajo cuyo aspecto serían qualia objetivas). Por consiguiente, las cualidades sensibles, si son reales, están en el objeto cuando, y sólo cuando, están en la mente. Mas por otra parte resulta en realidad que, a pesar de lo anterior, cuando las cualidades sensibles están en el objeto no podemos decir de ellas lo mismo que podemos decir cuando están en la mente. En efecto, cuando están en el objeto, como ya hemos visto, no tienen sujeto de inhesión, por lo que, de ser así, deberían tratarse como nombres y no como predicados. ${ }^{51}$ Ahora bien, si cuando están en el objeto la condición para que se conviertan en nombres es que el sujeto de inhesión haya desaparecido, cuando están en la mente esta condición no se cumple, puesto que Berkeley sigue concibiendo la mente como un sujeto sustancial. Siendo así ¿qué razón puede haber que impida tratar las cualidades sensibles, cuando están en la mente, como designaciones de atributos (o propiedades), es decir, como predicados? Lo importante es que están en la mente o en una sustancia espiritual; lo demás dependería de saber si están en ella como propiedades esenciales, y en este sentido el rechazo de Berkeley parece estar plenamente justificado, o si están en ella como distintas maneras de "aparecerse", y en este sentido el rechazo no está por lo menos claramente justificado. En resumen, el hecho de que, a pesar de que se considera que las qualia objetivas y las qualia sensibles son idénticas, las primeras pueden tratarse como nombres y las segundas como predicados, mostraria que donde parecía que se estaba haciendo referencia a idénticos designata, en realidad se estaba haciendo referencia a distintas designaciones; que en realidad no hay tales designata idénticos, sino únicamente distintas expresiones que corresponden a distintos tipos de lenguajes.

El otro ejemplo nos lo brinda Hume. Con frecuencia Hume habla de las impresiones sensibles como si se tratara de las impresiones que uno tiene "de la figura, el volumen, movimiento y solidez... de los colores, sabores, olores, sonidos, calor y frío"; 52 se propendería a creer, en este caso, que Hume se refiere a la figura, al volumen, a los colores y sonidos, etc., considerándolas como qualia objetivas, específica y causalmente independientes de las impresiones sensibles. En lo que cualquier realista podría convenir de alguna manera. Pero con no menor frecuencia Hume se refiere a las impresiones sensibles como si éstas fueran las qualia objetivas mismas, es decir, como si estas últimas se identificaran con la qualia sensibles mismas; como

50 Berkeley, P. H. K., \& 49 , p. 88.

51 Russell ha expuesto esto con claridad: cuando no hay más sujeto de inhesión, o sustancia, toda cualidad se convierte en un nombre y los predicados desaparecen ( $A n$ Inquiry into Meaning and Truth, ed. cit., cap. 6, p. 93).

52 Hume, T. H. N., I, iv, 2, p. 243. 
cuando afirma que la idea visual del oro "es un color amarillo", o cuando sostiene que la idea de sustancia, si se percibe por la vista o por los oídos, "debe ser un color" o "un sonido". ${ }^{33}$

Por supuesto, si por una quale objetiva, un color rojo, por ejemplo, se entiende, por una parte, una propiedad inherente a la naturaleza de un objeto, que es específica y causalmente independiente de las senso-percepciones, tal que por el color rojo se entienda una cierta longitud de onda del espectro o una propiedad disposicional inalterable -cosa que Hume no deja constantemente de plantearse-, y si por una quale sensible se entiende, por otra parte, una propiedad que debe su presentación y carácter sólo a la senso-percepción y a las condiciones en que ésta tiene lugar, un "rojo visual" en este caso, es claro que estas dos clases de qualia no son identificables. ${ }^{54} \mathrm{Y}$ sin embargo, utilizamos las mismas palabras para referirnos a unas y otras cualidades (como la palabra "rojo" en el presente ejemplo). La ambigüedad que se produce en el modo material de hablar, cuando decimos este objeto tiene la propiedad de ser rojo no visual, aunque también tiene la de ser rojo visual, desaparece tan pronto como la palabra "rojo" es referida a distintos sistemas de lenguaje. Así, nuestro segundo ejemplo muestra también que la manera en que Hume se refiere a las cualidades es equívoca, y que donde a él le parece que se está refiriendo a ciertos designata lo que hace de hecho es estarse refiriendo a designaciones de un cierto lenguaje.

Todo lo anterior significa que no podemos definir más al fenomenalismo mediante una definición formal o, nominal, digamos, como una doctrina filosófica en la que se sustenta que los objetos materiales se reducen a conjuntos de ideas de sensación, de datos sensibles, o como luego sostuvo J. S. Mill, a "grupos de posibilidades permanentes de sensación". 55 Requerimos ahora más bien de una definición contextual, de una definición por el uso, que defina el fenomenalismo, no ya como una filosofía que versa acerca de ciertas cuestiones de hecho y que las resuelve en términos de phenomena, sino como una filosofía que aspira a resolver los problemas característicos del fenomenalismo material, pero planteándolos como problemas lingüisticos, traduciéndolos al modo formal de hablar. Siguiendo este tipo de planteamiento y las directivas filosóficas que en un cierto momento señalaron Russell y Carnap, A. J. Ayer expresó ésta que podría considerarse como una definición semántica de lo que es el fenomenalismo formal: “...decir, como dicen los fenomenalistas, que los objetos físicos son construcciones lógicas a partir de datos sensibles... no significa que los objetos

53 T. H. N., I, i, 6, pp. 59-6o.

54 Cf., C. I. Lewis, "Realism or Phenomenalism?", The Philosophical Review, vol. LXIV, 1955, pp. 242-244.

55 J. S. Mill, Examination of Sir William Hamilton's Philosophy, cap. XI; recogido en Perception and the External World, editado por R. J. Hirst, Macmillan, New York, 1968, pp. $274^{-282 .}$ 
físicos se compongan literalmente de datos sensibles, o que los objetos físicos sean ficciones y reales únicamente los datos sensibles. Significa simplemente que los enunciados (statements) sobre objetos físicos son de algún modo reducibles a enunciados sobre datos sensibles, o como algunas veces se declara, que afirmar algo acerca de un objeto físico es afirmar algo, aunque no necesariamente lo mismo, acerca de datos sensibles". 56

Definido de esta manera, el fenomenalismo formal se nos presenta como una teoría de dos lenguajes, un lenguaje constituido por enunciados que se refieren a objetos físicos y otro constituido por enunciados que se refieren a datos sensibles, y además, como una tesis reduccionista en la que se propone la reducción del primer lenguaje al segundo. Mediante esta reformulación del fenomenalismo y este programa reduccionista se ha pretendido superar todos los riesgos que el fenomenalismo material creía correr admitiendo que existen y podemos conocer objetos físicos aun cuando éstos no sean percibidos, así como algunas paradojas que surgen cuando, aun admitiendo lo anterior, se los quiere explicar en términos de datos sensibles. Así, por ejemplo, representa un verdadero problema cómo pueda explicarse un objeto físico en términos de datos sensibles, toda vez que si se lo reduce a datos sensibles no existe cuando no es percibido, y si no existe cuando no es percibido entonces no es un objeto físico; por otra parte, si se sostiene que el objeto físico existe aun cuando no sea percibido -y ésta sería la forma más propia de concebir los objetos físicos- en este caso para explicarlo en términos de datos sensibles habrá que admitir que existen "datos sensibles no percibidos", o sensibilia; pero admitir estos últimos y admitir que existen sensibilia imperceptibles ya no hace ninguna diferencia, y el intento de explicación degenera en una explicación que deja de ser fenomenalista.57 Pues bien, problemas como éstos se plantean con menos riesgos si en lugar de manipular datos sensibles reales y posibles tratamos con un lenguaje de datos sensibles; desde este punto de vista el problema se limitaría a decidir si entre los enunciados que se refieren a datos sensibles, equivalentes a los que se refieren a objetos físicos, tienen derecho a figurar enunciados hipotéticos, esto es, enunciados en los que se afirme, no que tales o cuales datos sensibles ocurren, ocurrieron u ocurrirán, sino que en ciertas condiciones específicas ocurririan.58

En relación con el planteamiento formal de las cuestiones fenomena1 $32-133$.

56 A. J. Ayer, "Phenomenalism", Philosophical Essays, London, Macmillan, 1965, pp.

57 En el fondo, a esto apuntaba la crítica que en su momento hizo C. D. Broad al fenomenalismo que expuso Russell en Our Knowledge of the External World y que éste posteriormente abandonó persuadido de que "los objetos físicos no pueden ser interpretados como estructuras compuestas de elementos experimentados realmente" (My Philosophical Development, Allen \& Unwin, 1959, IX, p. 105). Cf., de Broad, "Phenomenalism", Proceedings of the Aristotelian Society, vol. XV, 1915, p. 237.

58 A. J. Ayer, op. cit., p. 133. 
listas, queda el problema de si la reducción programada es satisfactoria. El mismo Ayer sostiene, como hemos expuesto, que los enunciados sobre datos sensibles a que se reducen los enunciados sobre objetos físicos no tienen que afirmar "necesariamente lo mismo" que afirman estos últimos. ¿En qué sentido entonces se habría llevado a cabo.la reducción? Muchas de las oraciones en que aparecen designaciones de cosas u objetos físicos son categóricas. ¿En qué sentido entonces, como sostiene Carnap, tienen el mismo "sentido aseverativo" y son equipolentes con una clase de oraciones en que aparecen designaciones-de-datos-sensibles la mayoría de cuyos miembros son hipotéticos?

En suma, nos hemos referido especial y detenidamente al pensamiento de Berkeley y de Hume con el propósito de destacar qué deba entenderse por un fenomenalismo material del que ambos son expresiones radicales, con las diferencias aludidas; destacar a qué problemas responde -en particular los que se derivan de la teoría causal de la percepción-y qué problemas a su vez plantea: un dilema entre cuyos cuernos ni Berkeley ni Hume habrian podido escapar, un dilema que tampoco parece haber sido "cogido por los cuernos" ni por Ryle ni por el fenomenalismo formal que deriva de Russell y de Carnap, y que continúa siendo teatro de conflictos de la teoría del conocimiento en lo que responde al tema aquí discutido.

Wonfilio TREJo

Universidad Nacional Autónoma de México 